Received 00th January 20xx, Accepted 00th January 20xx DOI: $10.1039 / x 0 \times x 00000 x$

\title{
Endowing TADF Luminophors with AIE Properties Though Adjusting Flexible Dendrons for Highly Efficient Solution- Processed Nondoped OLEDs.
}

\author{
Jing Yi Wei, ${ }^{a}{ }^{\dagger}$ Dan Liu, ${ }^{a}{ }^{\dagger}$ Wen Wen Tian, ${ }^{a}$ Wei Jiang, ${ }^{a} *$ Yue Ming Sun, ${ }^{a}$ Zheng Zhao ${ }^{b}$ and Ben Zhong \\ Tang ${ }^{\mathrm{b} *}$
}

\begin{abstract}
The amalgamation of thermally activated delayed fluorescence (TADF) and aggregation-induced emission (AIE) properties, term AIE-TADF, is a promising strategy to design novel robust luminescent materials. Herein, we transform 2,3,4,5,6penta( $9 \mathrm{H}$-carbazol-9-yl)benzonitrile $(5 \mathrm{C} z \mathrm{BN})$ from an ACQ molecule to AlEgens by simply decorating a $5 \mathrm{CzBN}$ core with alkyl chain-linked spirobifluorene dendrons. By increasing the number of flexible dendrons, these materials can not only show obvious AIE-TADF characteristics and uniform film morphology, but also exhibit better resistance to isopropyl alcohol, which are beneficial to the fully solution-processed OLEDs. Notably, 5CZBN-PSP show great device efficiency with external quantum efficiency (EQE), current efficiency and power efficiency of $20.1 \%, 58.7 \mathrm{~cd} \mathrm{~A}^{-1}$ and $46.2 \mathrm{~lm} \mathrm{~W} \mathrm{~m}^{-1}$, respectively, which achieved record-breaking efficiency in solution-processed nondoped OLEDs based on AIE emitters. It demonstrates a general approach to explore new efficient emitters by the marriage of AIE and TADF what could potentially improve their performance in various areas.
\end{abstract}

\section{Introduction}

The reduction of manufacturing cost of organic light-emitting diodes (OLEDs) remains one of the key challenges in the commercialization of OLED technology. ${ }^{1}$ Compared with vacuum deposition, solution-process techniques are more promising to develop large-area fabrication because of high material utilization rate, simple manufacturing process, and easy operation. ${ }^{2-4}$ However, the efficiencies of solutionprocessed OLEDs are generally low, so more efficient luminescent materials urgently need to be developed.5,6 After the pioneering work by Adachi and co-workers, thermally activated delayed fluorescent (TADF) materials have been explored as the most promising third generation emitters following the conventional fluorescent materials, phosphorescent heavy-metal complexes. ${ }^{7-9}$ In addition, several small-molecule TADF emitters have been employed in the solution-processed OLEDs and achieved relatively high device

a Jiangsu Province Hi-Tech Key Laboratory for Bio-Medical Research, Jiangsu Engineering Laboratory of Smart Carbon-Rich Materials and Device, School of Chemistry and Chemical Engineering, Southeast University, Nanjing, 211189, China.

${ }^{b}$ Department of Chemistry, Hong Kong Branch of Chinese National Engineering Research, Center for Tissue Restoration and Reconstruction, The Hong Kong University of Science and Technology, Clear Water Bay, Kowloon, Hong Kong 999077, China.

+ Dan Liu and Jing Yi Wei are contributed equally to this work.

*Email: jiangw@seu.edu.cn (Wei Jiang), tangbenz@ust.hk (Ben Zhong Tang) Electronic Supplementary Information (ESI) available: Synthesis and characterization details, NMR spectra of compounds, CV curves, AFM images. photophysical properties and supplementary device performance. See DOI: 10.1039/x0xx00000x performance. ${ }^{10-12}$ It is vital but to emphasize that majority of TADF emitters are doped in appropriate host matrixes to weaken the intermolecular interactions and exciton quenching. ${ }^{13,14}$ As is known, strong luminescence of conventional organic fluorophores in dilute solution is normally weaken or quenched in their aggregated states, there is no exception to most TADF materials. ${ }^{15-17}$ Although long-lived triplet excitons in TADF molecules can be up-converted into radiable singlet excitons through the reverse intersystem crossing (RISC) process, the lower RISC rate ( $\left.\mathrm{k}_{\mathrm{RISC}}\right)$ inevitably makes many triplet excitons quenching in the aggregated state by triplet-triplet annihilation (TTA), singlet-triplet annihilation (STA) and triplet-polaron annihilation (TPA). ${ }^{18,19}$ The aggregation-caused quenching (ACQ) effect has seriously limits their applications and depresses the device performance. Fortunately, Tang and co-workers have reported series of new luminogens with aggregation-induced emission (AIE) property since 2001. ${ }^{20-22}$ These AIE compounds effectively overcome the drawbacks of ACQ and achieve the efficient solid-state luminescence. The enhance photoluminescent quantum yield (PLQY) in aggregation state enables the performances of the nondoped OLEDs to be improved. ${ }^{23-25}$

Based on the above research, TADF materials can harvest both singlet and triplet excitons to achieve theoretic $100 \%$ internal quantum efficiency, and AIE luminogens are favored to attain efficient emission in their condensed solid states. Therefore, integrating TADF emitters with AIE nature could be a feasible strategy to develop efficient solution-processed nondoped OLEDs. ${ }^{26}$ In this design concept, various types of AIETADF materials have been reported in recent years by Tang and 


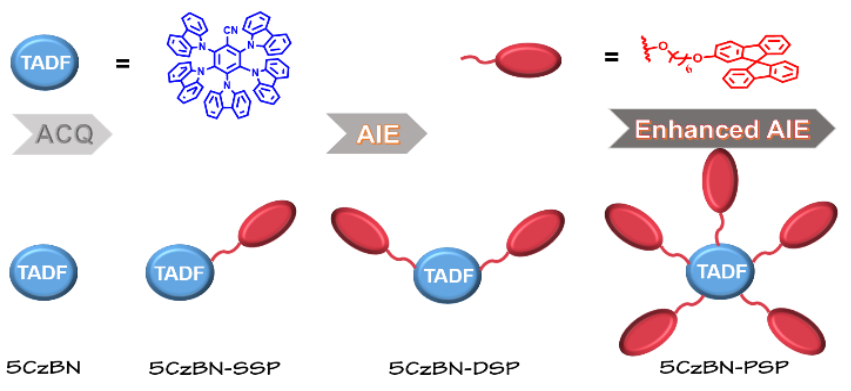

Figure 1 Concept of core-dendron system in nondoped emissive layer and chemical structures of $5 \mathrm{CzBN}, 5 \mathrm{CzBN}-\mathrm{SSP}, 5 \mathrm{CzBN}-\mathrm{DSP}$ and $5 \mathrm{CzBN}-\mathrm{PSP}$.

Chi, et al. ${ }^{27-29}$ Despite the nondoped devices exhibited improved electroluminescent efficiencies, further utilization of these emitters in the solution process has been rarely explored. ${ }^{30}$ This is mainly due to many inevitable challenges that need to overcome. (i) most of the AIE-TADF materials have poor solubility, making them unsuitable for nondoped solution process. (ii) High crystallization of AIE-TADF materials in film states can lead to the generation of dark current and exciton trap, eventually reduce device performance. (iii) In a long run, the common AIE-TADF materials cannot resist the erosion of solvent used for the processing upper layers, which limited their further development in fully solution-processed OLEDs. Therefore, there keeps a large room and challenge to extend the structural diversity of solution-processable AIE-TADF materials and enhance their device performances.

In this contribution, a novel type of AIE-TADF molecules were developed by constructing core-dendron structure, which has not been report in previous research. we designed and synthesized three AIE-TADF molecules named $5 \mathrm{CzBN}-\mathrm{SSP}$, $5 \mathrm{CzBN}-\mathrm{DSP}$ and $5 \mathrm{CzBN}-\mathrm{PSP}$. The core molecule was 2,3,4,5,6penta(9H-carbazol-9-yl)benzonitrile (5CzBN), which exhibits TADF characteristics. The flexible dendrons were different numbers of alkyl chain-linked spirobifluorene. Owing to increased molecular weight and solubilizing alkyl chains, these materials showed good film morphology and are suitable for solution process. More interestingly, Although the core $5 \mathrm{CzBN}$ and dendron spirobifluorene all displayed ACQ properties, the core-dendron materials demonstrated AIE phenomenon. With increasing the numbers of flexible branches, the compounds showed better solubility, more smooth surface morphology, more obvious AIE feature and higher photoluminescent quantum yields (PLQYs). By employing these AIE-TADF materials (5CzBN-SSP, 5CzBN-DSP, 5CzBN-PSP) as emitter, the fully solution-processed nondoped OLEDs achieved high efficiency external quantum efficiency (EQE) of $7.3 \%, 13.9 \%$ and $20.1 \%$, which far exceed the fully solution processed OLEDs based on $5 \mathrm{CzBN}$. Furthermore, it is worth mentioning that the OLED based on 5 CzBN-PSP showed a record-breaking external EQE of $20.1 \%$ in the area of solution-processed nondoped OLEDs based on AIE emitters so far. The core-dendron system will provide a good candidate for highly efficient solution-processed nondoped OLEDs.

\section{Results and Discussion}

2,3,4,5,6-penta(9H-carbazol-9-yl)benzonitrile (5CzBN) was selected as the TADF emitter unit, the alkyl chain-linked spirobifluorene was used as the functional dendrons. The preparation of the target compounds $3-(4-((6-)(9,9)-$ spirobi[fluoren]-2-yloxy)hexyl)oxy) -9H-carbazol-9-yl)-2,4,5,6tetra(9H-carbazol-9-yl)benzonitrile (5CzBN-SSP), 3,5-bis(4-((6(9,9'-spirobi[fluoren]-2-yloxy)hexyl) oxy)-9H-carbazol-9-yl)2,4,6-tri(9H-carbazol-9-yl)benzonitrile. (5CzBN-DSP) and 2,3,4,5, 6-5 (4 - ((9,9' -fluorene) -2-hydroxyl) ethyl) -9h-carbazole-9-yl) benzonitrile ( $5 \mathrm{CzBN}-\mathrm{PSP})$ was carried out by the synthetic procedure shown in Scheme 1 and Scheme S1. All the AIE-TADF compounds are synthesized through catalyst free aromatic nucleophilic substitution reactions. Before device fabrication, the target product was separated and purified by silica gel column.

The thermal stability properties of $5 \mathrm{CzBN}-\mathrm{SSP}, 5 \mathrm{CzBN}-\mathrm{DSP}$ and $5 \mathrm{CzBN}-\mathrm{PSP}$ were characterized by the thermal gravity analysis (TGA) and differential scanning calorimetry (DSC) under the nitrogen atmosphere at a heating rate of $10^{\circ} \mathrm{C} / \mathrm{min}$. As is shown in Figure $\mathrm{S} 1$, the decomposition temperatures $\left(T_{d}\right)$ with $5 \%$ weight loss of $5 \mathrm{CzBN}-\mathrm{SSP}, 5 \mathrm{CzBN}-\mathrm{DSP}$ and $5 \mathrm{CzBN}-\mathrm{PSP}$ were $406.2^{\circ} \mathrm{C}, 394.7^{\circ} \mathrm{C}$ and $393.8^{\circ} \mathrm{C}$, which demonstrated that all three emitters have high thermal stability. The glass transition

Table1 Basic thermal, photophysical and electrochemical parameters of 5CzBN-SSP, 5CzBN-DSP and 5CzBN-PSP.

\begin{tabular}{|c|c|c|c|c|c|c|c|c|c|c|c|}
\hline compounds & $\begin{array}{c}\mathrm{T}_{\mathrm{g}} / \mathrm{T}_{\mathrm{d}}{ }^{\mathrm{a}} \\
{\left[{ }^{\circ} \mathrm{C}\right]}\end{array}$ & $\begin{array}{l}\lambda_{a b s}{ }^{b} \\
{[n m]}\end{array}$ & $\begin{array}{c}\lambda_{\mathrm{em}} \mathrm{c} / \mathrm{d} / \mathrm{e} \\
{[\mathrm{nm}]}\end{array}$ & $\tau_{p}^{f} / \tau_{d}^{f}$ & $\begin{array}{c}\mathrm{FWHM}^{\mathrm{c} / \mathrm{d} / \mathrm{e}} \\
{[\mathrm{nm}]}\end{array}$ & $\begin{array}{l}\mathrm{E}_{g}^{\mathrm{g}} \\
(\mathrm{eV})\end{array}$ & $\begin{array}{l}\mathrm{T}_{1}^{\mathrm{h}} \\
{[\mathrm{eV}]}\end{array}$ & $\begin{array}{l}\text { HOMO }^{j} \\
{[\mathrm{eV}]}\end{array}$ & $\begin{array}{l}\text { LUMOk }^{\text {LeV] }} \\
\text { [eV }\end{array}$ & $\begin{array}{c}\mathrm{S}_{1} \\
{[\mathrm{eV}]}\end{array}$ & $\begin{array}{c}\Delta \mathrm{E}_{\mathrm{ST}}{ }^{1 / m} \\
{[\mathrm{eV}]}\end{array}$ \\
\hline $5 \mathrm{CzBN}-\mathrm{SSP}$ & $\begin{array}{l}166.8 / \\
406.2\end{array}$ & 229/275/310 & $515 / 502 / 473$ & $38 \mathrm{~ns} / 3.1 \mu \mathrm{s}$ & $96 / 81 / 85$ & 2.73 & 2.80 & -5.66 & -2.93 & 2.96 & $0.16 / 0.15$ \\
\hline $5 C z B N-D S P$ & $\begin{array}{c}163.7 / \\
394.7\end{array}$ & $230 / 285 / 310$ & $517 / 504 / 476$ & $56 \mathrm{~ns} / 3.8 \mu \mathrm{s}$ & $88 / 78 / 80$ & 2.75 & 2.78 & -5.65 & -2.90 & 2.93 & $0.15 / 0.13$ \\
\hline $5 \mathrm{CzBN}-\mathrm{PSP}$ & $\begin{array}{c}144.2 / \\
393.8\end{array}$ & $230 / 288 / 312$ & $523 / 504 / 480$ & $77 \mathrm{~ns} / 4.5 \mu \mathrm{s}$ & $110 / 71 / 74$ & 2.70 & 2.74 & -5.63 & -2.86 & 2.87 & $0.13 / 0.11$ \\
\hline
\end{tabular}

${ }^{a} \mathrm{~T}_{\mathrm{d}}$ corresponding to $5 \%$ weight loss. b ${ }^{\mathrm{B}}$ Measured in $\mathrm{CH}_{2} \mathrm{Cl}_{2}$ solution at the room temperature. ${ }^{\mathrm{c}, \mathrm{d}, \mathrm{e}}$ measured in $\mathrm{CH}_{2} \mathrm{Cl}_{2}$ solution, neat film and toluene solution at $298 \mathrm{~K}$. ${ }^{\mathrm{f}} \mathrm{Prompt}$ and delayed fluorescence lifetimes of the neat film at room temperature. ${ }^{8}$ Estimated from the absorption edges in the neat film. ${ }^{\mathrm{h}} \mathrm{Estimated}$ from the peak of the phosphorescence spectra in toluene at $77 \mathrm{~K}$. The onset potential of oxidation as reference to ferrocene $(\mathrm{Fc})$. The HOMO energies was determind from the onset potentials for oxidation with regard to the energy level of ferrocene( $4.8 \mathrm{eV}$ below vacuum). ${ }^{k}$ Calculated from the HOMO and optical energy gap. 'Different between $\mathrm{S}_{1}$ energy and $\mathrm{T}_{1}$ energy. ${ }^{\mathrm{m} R e s u l t s}$ of the DFT calculation. 
temperatures $\left(\mathrm{T}_{\mathrm{g}}\right)$ of $5 \mathrm{CzBN}-\mathrm{SSP}, 5 \mathrm{CzBN}-\mathrm{DSP}$ and $5 \mathrm{CzBN}-\mathrm{PSP}$ were $166.8^{\circ} \mathrm{C}, 163.7^{\circ} \mathrm{C}$ and $144.2^{\circ} \mathrm{C}$, respectively. The high $\mathrm{T}_{\mathrm{g}}$ values ensured that both three materials can form uniform amorphous films during the solution process. However, when the number of branches gradually increases, the values of $T_{d}$ and $T_{\mathrm{g}}$ decrease to some extent. Besides, we also investigated the morphology of the nondoped films by spin coating (Figure S2). The films of $5 \mathrm{CzBN}-\mathrm{SSP}, 5 \mathrm{CzBN}-\mathrm{DSP}$ and $5 \mathrm{CzBN}-\mathrm{PSP}$ are very smooth and the root-mean-square values are $0.50 \mathrm{~nm}, 0.43 \mathrm{~nm}$ and $0.38 \mathrm{~nm}$, respectively. The values are better than that of $5 \mathrm{CzBN}(0.74 \mathrm{~nm}) .{ }^{31}$ It suggests that all three materials can form the uniform amorphous films through the solution process. Hence, it is convinced that the flexible chain-linked spirobifluorene units can remarkably decrease the crystallization tendency and suppress the aggregation between the molecules. The better solubility and morphology are more beneficial to fabricate highly efficient fully solution processed OLEDs.

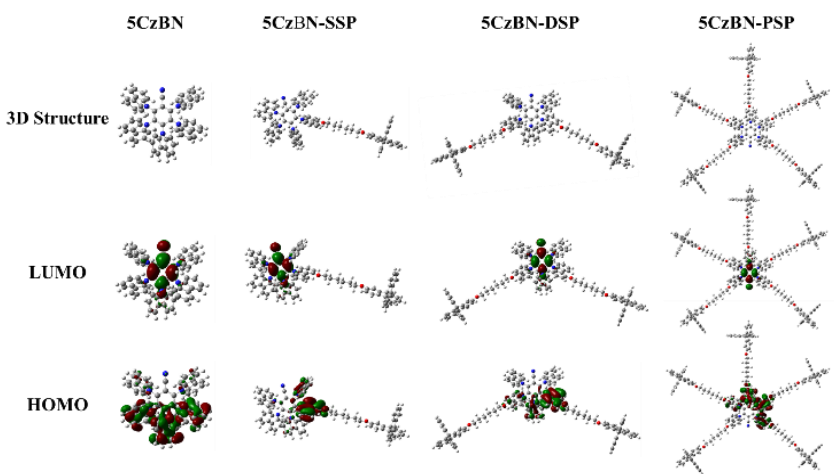

Figure 2 Optimized geometries and electron cloud distribution maps of $5 \mathrm{Cz} z \mathrm{BN}, 5 \mathrm{CzBN}$ SSP, 5CzBN-DSP and 5CzBN-PSP.

The electronic properties of $5 \mathrm{CzBN}, 5 \mathrm{CzBN}-\mathrm{SSP}, 5 \mathrm{CzBN}-\mathrm{DSP}$ and 5 CzBN-PSP were researched by density functional theory (DFT) calculations at the B3LYP of theory with the 6-31 G (d) as the basic set. The calculated results are shown in Figure 2, the highest occupied molecular orbital (HOMOs) electron clouds of all four materials are mainly located on the carbazolyl group of the emissive core, while the lowest unoccupied molecular orbital (LUMOs) electron clouds are mainly located on the electron-deficient benzonitrile units. Compared with the $5 \mathrm{CzBN}$ emitter $(-5.54 \mathrm{eV})$, the HOMO levels and the calculated energy gap between $\mathrm{S}_{1}$ and $\mathrm{T}_{1}\left(\Delta \mathrm{E}_{\mathrm{ST}}\right)$ of $5 \mathrm{CzBN}-\mathrm{SSP}, 5 \mathrm{CzBN}-\mathrm{DSP}$ and 5CzBN-PSP are $-5.36 \mathrm{eV} / 0.15 \mathrm{eV},-5.35 \mathrm{eV} / 0.13 \mathrm{eV}$ and -5.25 $\mathrm{eV} / 0.11 \mathrm{eV}$, respectively. They changed regularly with the increasing of electron-donating group spirobifluorene. Thus, it is concluded that more spirobifluorene dendrons can make the levels of HOMO shallower. In addition, the smaller $\Delta \mathrm{E}_{S T}$ ensure efficient RISC and subsequently efficient TADF emission. The electrochemical properties were measured by using the cyclic voltammetry (CV). As is shown in Figure S3, the energy levels of HOMO of 5 CzBN-SSP, 5CzBN-DSP and 5CzBN-PSP are -5.66, 5.65 and $-5.63 \mathrm{eV}$, respectively. and the result is no great difference with DFT calculations. According to the equation $E_{\text {LUMO }}=E_{\text {Hомо }}+E_{g}$, where $E_{g}$ is the optical band gap calculated from absorption spectra, the energy of LUMO about $5 \mathrm{CzBN}-\mathrm{SSP}$,
5CzBN-DSP and 5CzBN-PSP are $-2.93,-2.90$ and $-2.86 \mathrm{eV}$, respectively. When increasing the alkyl chain, the energy levels of LUMO and HOMO both increase slightly. (Table 1).

The photophysical properties of three TADF materials were measured by ultraviolet-visible (UV-Vis) absorption and fluorescence spectrometer. As is depicted in the Figure 3 and Figure S3, the absorption bands at $300-400 \mathrm{~nm}$ can be attributed to the $\pi-\pi^{*}$ band of Cz units, and a band at about 400$450 \mathrm{~nm}$ resulted from the ICT transitions. ${ }^{32}$ The energy band gaps $\left(E_{g}\right)$ of three materials were calculated as $2.73,2.75,2.77$ $\mathrm{eV}$ from the edge of the absorption. Also, the photoluminescence (PL) and phosphorescence (Phos) spectra were measured in toluene at room temperature and at $77 \mathrm{~K}$. All data are summarized in Table 1. The PL spectra of $5 \mathrm{CzBN}-\mathrm{SSP}$, $5 \mathrm{CzBN}-\mathrm{DSP}$ and $5 \mathrm{CzBN}-\mathrm{PSP}$ in toluene showed the emission bands at 473,476 and $480 \mathrm{~nm}$, respectively, while in $\mathrm{CH}_{2} \mathrm{Cl}_{2}$ they showed at 515,517 and $523 \mathrm{~nm}$. which means that the $\mathrm{S}_{1}$ states of three compounds are charge-transfer (CT) states. The $\mathrm{S}_{1}$ energy levels of $5 \mathrm{CzBN}-\mathrm{SSP}, 5 \mathrm{CzBN}-\mathrm{DSP}$ and $5 \mathrm{CzBN}-\mathrm{PSP}$ were calculated to be 2.96, 2.93 and $2.87 \mathrm{eV}$ in toluene. The lowtemperature $\mathrm{PL}$ at $77 \mathrm{~K}$ was monitored to evaluate the triplet energy levels $\left(\mathrm{T}_{1}\right)$ of $5 \mathrm{CzBN}-\mathrm{SSP}, 5 \mathrm{CzBN}-\mathrm{DSP}$ and $5 \mathrm{CzBN}-\mathrm{PSP}$, yielding values of $2.80,2.78$ and $2.74 \mathrm{eV}$, respectively. Subsequently, $\Delta \mathrm{E}_{\mathrm{ST}}$ values of $0.16,0.15$ and $0.13 \mathrm{eV}$ were respectively obtained for $5 \mathrm{CzBN}-\mathrm{SSP}, 5 \mathrm{CzBN}-\mathrm{DSP}$ and $5 \mathrm{CzBN}$ PSP by following the literature methods. ${ }^{33}$ The PL spectra and UV-vis spectra of the spin-coating film are shown in Figure S4, the emission wavelength of all compounds in the film state was redshifted by $25-30 \mathrm{~nm}$ relative to that of the solution states, demonstrating weak intermolecular interactions. Furthermore, all three materials exhibit bathochromic shift accompanied by the increase of solvent polarity (Figure S5). The large solvatochromic shift indicates that three compounds exhibit typical ICT characteristics. ${ }^{34}$ Notably, the wavelength of $5 \mathrm{CzBN}$ PSP is shifted by a smaller amount than those of $5 \mathrm{CzBN}-\mathrm{SSP}$ and $5 \mathrm{CzBN}-\mathrm{DSP}$ due to sufficient encapsulation by large numbers of spirobifluorene dendrons.
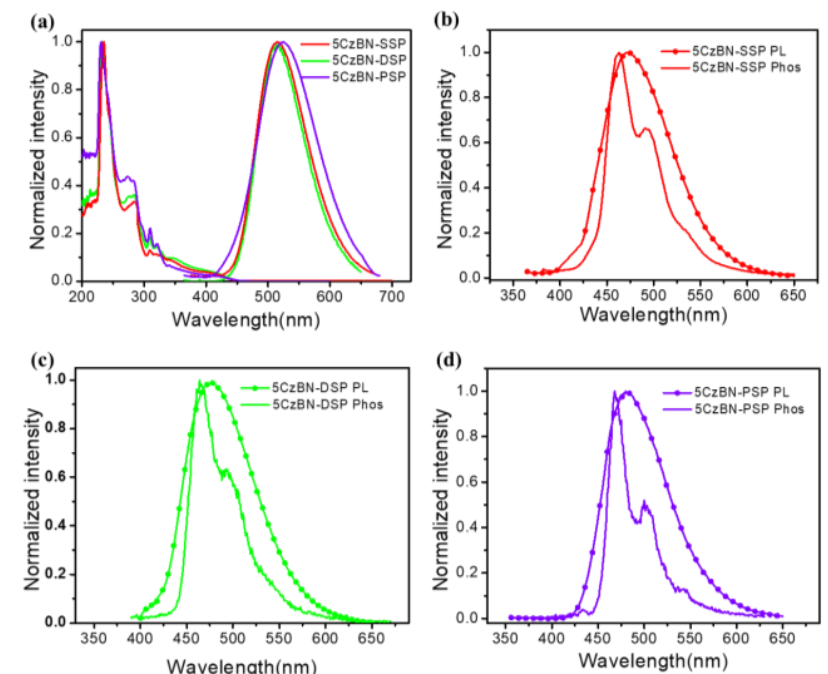

Figure 3 (a) UV-vis absorption and fluorescence spectra of 5 CzBN-SSP, 5CzBN-DSP and $5 \mathrm{C} z \mathrm{BN}-\mathrm{PSP}$ in $\mathrm{CH}_{2} \mathrm{Cl}_{2}$, (b) fluorescence, and phosphorescence spectra of $5 \mathrm{CzBN}-\mathrm{SSP}$ in toluene, (c) fluorescence, and phosphorescence spectra of 5CzBN-DSP in toluene, (d) fluorescence, and phosphorescence spectra of $5 \mathrm{Cz} B \mathrm{BN}-\mathrm{PSP}$ in toluene. 
(a)

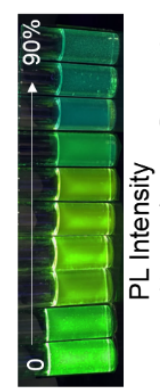

(c)

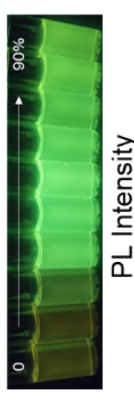

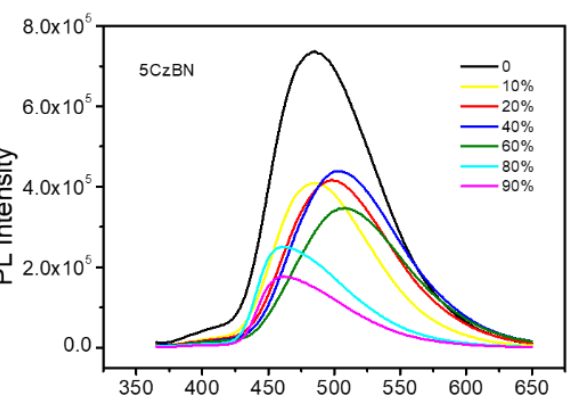

Wavelength $(\mathrm{nm})$

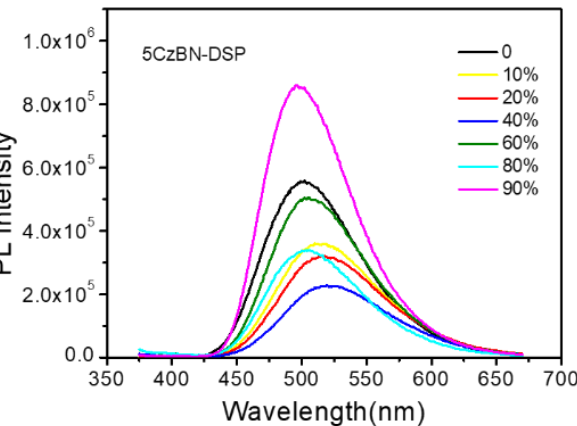

(b)
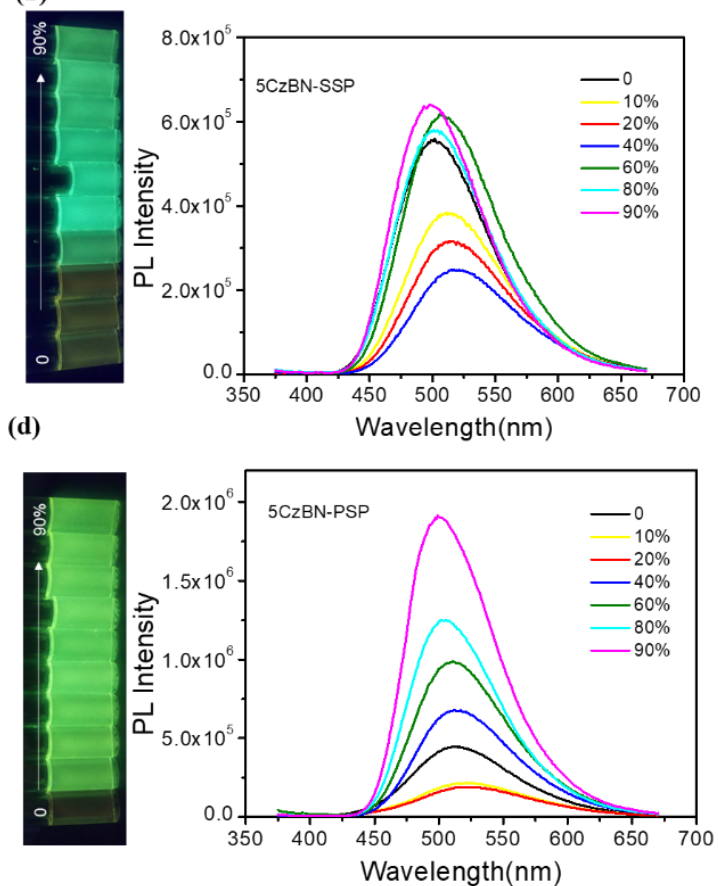

Figure 4 PL spectra and emission images of (a) 5CZBN (b) 5CZBN-SSP, (c) 5CZBN-DSP, (d) 5 CZBN-PSP in THF-water mixtures (10-5 M) with different fraction of water, respectively, under $365 \mathrm{~nm}$ UV irradiation.

In order to explore the AIE feature of these materials, the PL intensity in the mixer of tetrahydrofuran (THF) and deionized water with various deionized water ratio fractions were measured and depicted in Figure 4 and $5 \mathrm{a}$. For $5 \mathrm{CzBN}$, the PL intensity showed an overall slow decline when water fractions $\left(f_{w}\right)$ increased from $0 \%$ to $90 \%$, even if there is a slight rise between $20 \%-40 \%$. This is typical ACQ phenomenon. However, by increasing the flexible dendrons, the PL intensity of three compounds showed different trends (AIE trends), especially for 5 CzBN-PSP. 5CzBN-PSP achieved out the significant fluorescence enhancement from $20 \%$ to $90 \%$, and the $\mathrm{PL}$ intensity in $90 \%$ mixtures is more than 4 times stronger than the initial intensity ( $\left.\mathrm{I}_{0}\right)$. 5CzBN-SSP and 5CzBN-DSP also exhibited a slight enhancement of the PL intensity when the $f_{W}$ was increased from $40 \%$ to $90 \%$. Thus, these results provide significant evidence to prove the AIE properties of three compounds, though the degree of AIE enhancement differed for each molecule. ${ }^{35-37}$ More interestingly, the peak of $5 \mathrm{CzBN}$ underwent a red-shift with increasing addition of water in the mixed solvent until molecular aggregation was induced to form nano-aggregates. Thereafter, the emission demonstrated a blue-shift until increasing concentration to $90 \%$. The same phenomenon can be observed in $5 \mathrm{CZBN}-\mathrm{SSP}, 5 \mathrm{CzBN}-\mathrm{DSP}$ and $5 \mathrm{CzBN}-\mathrm{PSP}$. And this is caused by a twisted intramolecular charge transfer (TICT) process. ${ }^{38}$ Before generation of the aggregates, solvatochromism accounts for the red-shift of emission peak with increasing solvent polarity. On the contrary, after generation of nano-aggregates, the intramolecular rotation is restricted and the local environment becomes less polar, thereby resulting in a blueshift in the emission color. The curves of the emission wavelength versus water fraction were shown obviously in Figure $5 \mathrm{a}$. some differences can also be found in this picture. With the increase in the number in spirobifluorene branches, the change in emission wavelength becomes smaller and smaller. It suggested that with increasing the number of dendrons, the TICT process is suppressed efficiently, the influence of the environmental polarity on the emission color of the materials becomes weak. Simultaneously, the AIE feature of dendrimers is more outstanding. From these results, it was confirmed that the AIE phenomenon that not existing in $5 \mathrm{CzBN}$ is emerging and enhancing in $5 \mathrm{CzBN}-\mathrm{SSP}$, $5 C z B N-D S P$ and $5 C z B N-P S P$. Furthermore, it can also be anticipated that the great AIE character for $5 \mathrm{CzBN}$-PSP should be more favourable as an emitter for the highly efficient solution-processed nondoped OLEDs. ${ }^{39}$

To better understand the TADF features of three compounds, the transient PL decay profiles were measured in the films. As is depicted in Figure 5, the PL decays of three molecules both exhibit bi-exponential decays which show prompt and delayed lifetimes of the components, fully demonstrated that $5 \mathrm{CzBN}$, $5 \mathrm{CzBN}-\mathrm{SSP}, 5 \mathrm{CzBN}-\mathrm{DSP}$ and 5CzBN-PSP are apparent TADF materials. ${ }^{35}$ And the data of three compounds are presented in
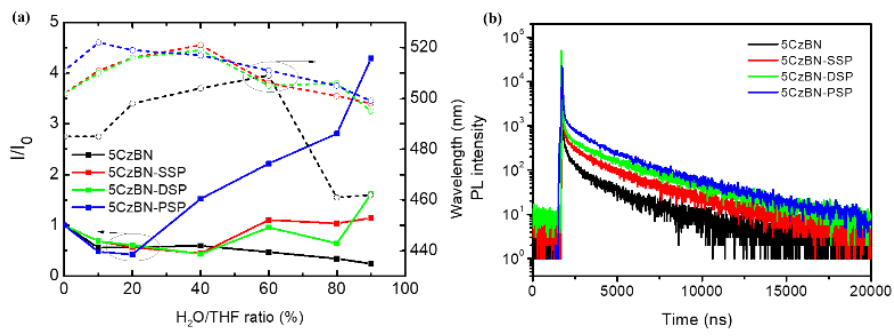

Figure 5 (a) The plots of fluorescence ratio $(1 / 10)$ and peak wavelength versus water volume fraction (b) Transient PL decay spectra in neat film measured at room temperature for 5CzBN-SSP, 5CzBN-DSP and 5CzBN-PSP. 

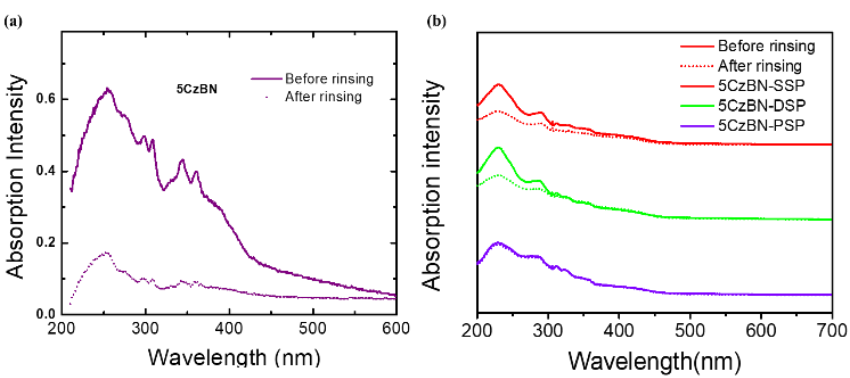

Figure 6 Absorption spectra before and after rinsing with isopropanol of $5 \mathrm{C} z \mathrm{BN}$ (a), 5 CzBN-SSP, 5CzBN-DSP and 5CzBN-PSP (b).

the Table 1. The transient lifetime of three compounds comes from the conventional fluorescence from $S_{1}$ to $S_{0}$. The delay lifetime is attributed to the reverse intersystem crossing (RISC) process from the non-radiative $T_{1}$ state to the radiative $S_{1}$ state to $S_{0}$ because of the small $\Delta E_{S T}$. Thus, the PL decay revealed that three molecules have TADF features. The delayed fluorescence lifetimes became longer with increasing the flexible dendrons. Besides, the PLQYs of 5CzBN-SSP, 5CzBN-DSP and 5CzBN-PSP in the neat films were also measured to research the emission feature. As shown in Table 2, the PLQYs of $5 \mathrm{CzBN}-\mathrm{SSP}, 5 \mathrm{CzBN}$ DSP and 5CzBN-PSP are $38.0 \%, 45.7 \%$, and $69.6 \%$, respectively. $5 \mathrm{CzBN}-\mathrm{PSP}$ has higher PLQY than other materials. It depicted that increasing the alkyl chain-linked dendrons can improve the PLQY by suppressing the core's collision. It is more beneficial to fabricate the excellent nondoped fully solution-processed OLED.

Before fabricating the fully solution processed OLEDs, alcohol resistance was measured by UV-Vis absorption spectroscopy. 40 As is shown in Figure 6, the variations in absorption intensity of $5 \mathrm{CzBN}, 5 \mathrm{CzBN}-\mathrm{SSP}, 5 \mathrm{CzBN}-\mathrm{DSP}$ and $5 \mathrm{CzBN}-\mathrm{PSP}$ before and after spin-rinsing with the isopropanol alcohol, the isopropanol alcohol would be used to processing the adjacent electron-transport layer (ETL). The absorption
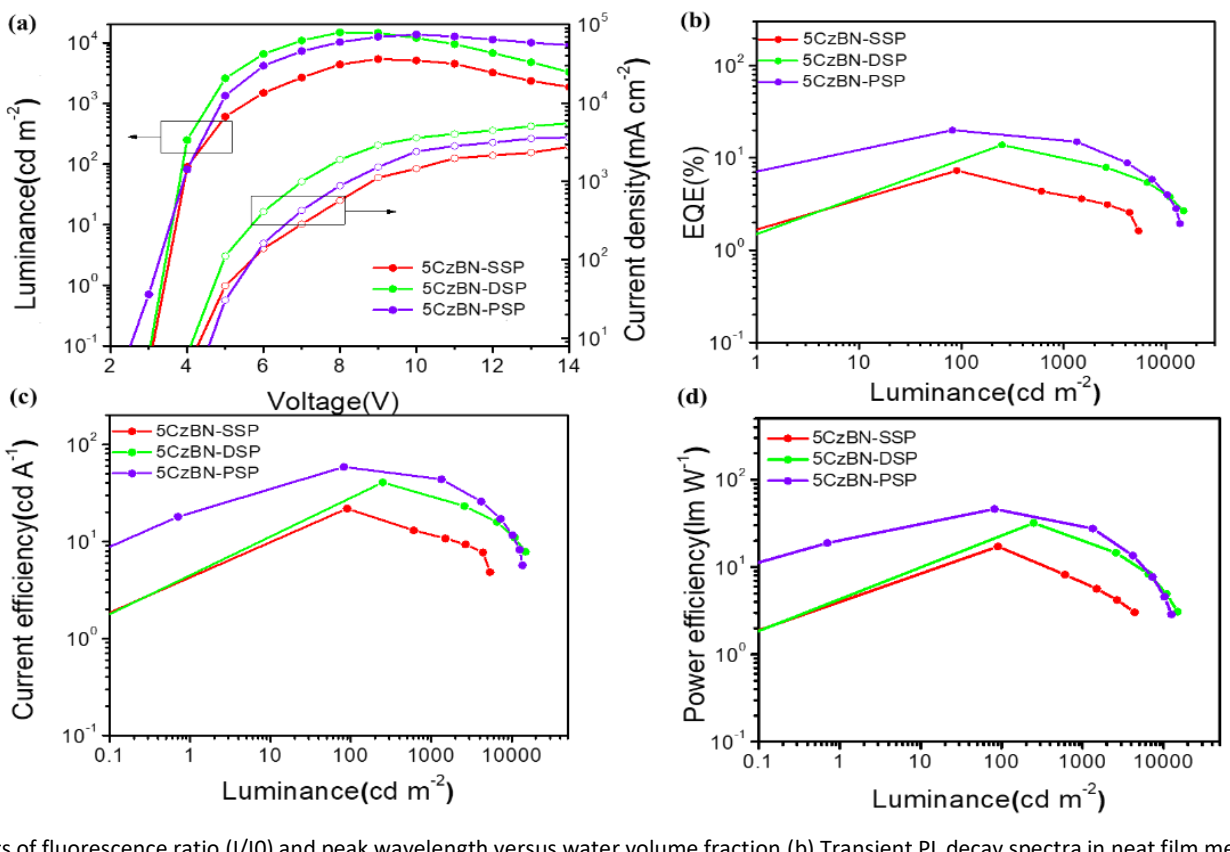

Figure 7 (a) The plots of fluorescence ratio $(\mathrm{I} / \mathrm{IO})$ and peak wavelength versus water volume fraction (b) Transient PL decay spectra in neat film measured at room temperature for

$5 \mathrm{CzBN}-\mathrm{SSP}, 5 \mathrm{CzBN}-\mathrm{DSP}$ and 5CzBN-PSP.

intensity of $5 \mathrm{C} z \mathrm{BN}-\mathrm{SSP}, 5 \mathrm{CzBN}-\mathrm{DSP}$ and $5 \mathrm{C} z \mathrm{BN}-\mathrm{PQP}$ remain nearly constant while the $5 \mathrm{CzBN}$ film is rinsed seriously by isopropanol alcohol. So it proves that the core would be encapsulated more sufficiently by introducing more alkyl chainlinked spirobifluorene dendrons. The compounds are more resistant to isopropanol alcohol. In other words, by increasing the number of dendrons, the materials can adequately prevent the redissolution by isopropanol.

In order to investigate the electro-luminescence (EL) properties of three AIE-TADF materials, nondoped OLED devices have been fabricated by using the solution-processed nondoped emission layer (EML) and electron-transport layer (РОT2T: (((1,3,5-triazine -2, 4,6-triyl) tris (benzene-3,1-diyl)) tris (diphenylphosphineoxide)))). The structures of three devices were indium-tin oxide (ITO)/ PEDOT: PSS (40 nm, spincoated)/EML (40 nm, spin-coated)/POT2T (40 nm, spincoated)/ $/ \mathrm{Cs}_{2} \mathrm{CO}_{3}(2 \mathrm{~nm}) / \mathrm{Al}(100 \mathrm{~nm})$. In this structure, PEDOT: PSS and POT2T served as the hole and electron transport materials, and $\mathrm{Cs}_{2} \mathrm{CO}_{3}$ was used as an electron injection layer. The schematic energy-level diagrams and the fabrication process of the devices are shown in Figure 7. These materials are all spin-coated to serve as the emission layer.

The devices with three compounds showed green emission with a peak positioned at $512 \mathrm{~nm}$. Figure 7 shows the Luminance-Voltage-Current density (L-V-J) and other EL properties about these devices, and the data of devices are summarized in Table 2. Figure $\mathrm{S} 6$ shows the EL spectra of $5 \mathrm{CzBN}$ SSP, 5CZBN-DSP and 5CZBN-PSP have the similar emission. The turn-on voltages of $5 \mathrm{CzBN}-\mathrm{SSP}, 5 \mathrm{CzBN}-\mathrm{DSP}$ and $5 \mathrm{CzBN}-\mathrm{PSP}$ are $3.4 \mathrm{~V}, 3.2 \mathrm{~V}$ and $3.1 \mathrm{~V}$. The maximum luminance, $C E, P E, E Q E$ of 5 CzBN-PSP are $58.7 \mathrm{~cd} \mathrm{~A}^{-1}, 46.2 \mathrm{Im} \mathrm{W}^{-1}$ and $20.1 \%$, respectively, (Table 2), which was the highest efficiency in this work. It indicated that the AIE-TADF dendrimers can suppress exciton quenching of the emitter core, ${ }^{41}$ and the good film-forming 
properties and the high efficiencies can be approved by increasing the more branches to the core of the materials. All in all, regulating peripheral dendritic branched chains provided a new method for the preparation of full wet devices in the future.

\section{Conclusions}

In summary, a series of new core-dendron materials with AIETADF characteristics have been synthesized and studied by adjusting the number of the alkyl chain-linked spirobifluorene dendrons. With the increasing numbers of spirobifluorene dendrons, 5CzBN-PSP exhibited both significant TADF and AIE features. Furthermore, it showed better resistance to the isopropyl alcohol than 5 CzBN-SSP and 5CZBN-DSP, the device of $5 \mathrm{CzBN}-\mathrm{PSP}$ achieved a maximum external quantum efficiency of $20.1 \%$, current and power efficiency of $58.7 \mathrm{~cd} \mathrm{~A}^{-1}$ and $46.2 \mathrm{Im}$ $\mathrm{W}^{-1}$, which is more efficient than the performance of fully solution-processed OLEDs based on the traditional TADF materials. Our research indicated that adjusting the numbers of the alkyl-chains linked spirobifilorene to the TADF cores can transform the common fluorophores even ACQ molecules into new AIE molecules. This work thus opens up a new route to design new AIE-TADF emitters with efficient performance in optoelectronic applications.

\section{Experimental section}

\section{General methods}

All solvents and materials were used as received from commercial sources without further purification. The anhydrous tetrahydrofuran (THF) solvent was dewatered according to standard procedures. ${ }^{1} \mathrm{H}$ NMR and ${ }^{13} \mathrm{C}$ HMR spectra were recorded on a BRUKER AMX $600-\mathrm{MHz}$ instrument. Elemental analysis was determined by an Elementar Vario EL $\mathrm{CHN}$ elemental analyzer. Mass spectrometry was performed with a Thermo Electron Corporation Finnigan LTQ mass spectrometer. The UV-Vis absorption spectra of the compounds were measured by SHIMADZU UV-2450. The absolute PLQYs of these materials were measured with a Hamamatsu Quantaurus-QY C11347 spectrometer. The photoluminescence emission spectra were recorded on HORIBA FLUOROMAX-4 and liquid nitrogen was placed into the optical Dewar flask for low temperature (77K) photophysical measurements. Thermogravimetric analysis (TGA) and Different scanning calorimetry (DSC) curves were recorded with a Netzsch simultaneous thermal analyzer (STA) system
(STA409PC) and DSC 2910 modulated calorimeter under a dry nitrogen gas flow at a heating rate of $10{ }^{\circ} \mathrm{C} \mathrm{min}-1$. Cyclic voltammetry (CV) was performed on a $\mathrm{CHI750C}$ voltammetric analyzer in a typical three-electrode cell with a platinum plate working electrode, a platinum wire counter electrode and a silver wire reference electrode. The supporting electrolyte was tetrabutylammonium hexafluorophosphate (0.1M) and ferrocene was selected as the internal standard. AFM (Seiko Instruments, SPA-400) was used to measure the film surface morphology. The measured pure film were formed by spincoating and the solvent is 1,2-dichloroethane. The optimized structure was calculated by Gaussian09 at the B3LYP functional with 6-31G(d) basis sets. The molecular orbitals were visualized using Gaussview 5.0.

\section{Device Fabrication and Measurements}

ITO-coated glass substrates were rinsed in deionized water and then ultrasonicated sequentially in acetone and ethanol. Before device fabrication, the ITO substrate was treated in a UV-ozone oven for $20 \mathrm{~min}$. Then a $40 \mathrm{~nm}$ thick poly(3,4ethylenedioxythiophene): poly(styrenesulfonate) (PEDOT: PSS) film was first deposited on the pre-cleaned ITO glass substrates and baked at $150^{\circ} \mathrm{C}$ for $10 \mathrm{~min}$. Then, an EML with a thickness of about $40 \mathrm{~nm}$ was spin-coated from 1, 2-dichloroethane solution onto the PEDOT: PSS layer and annealed at $100^{\circ} \mathrm{C}$ for $30 \mathrm{~min}$ to remove the residual solvent at the atmosphere of $\mathrm{N}_{2}$. PO-T2T was spin-coated from isopropanol solution as the electron transporting layer, respectively. Finally, $2 \mathrm{~nm}$ thick $\mathrm{Cs}_{2} \mathrm{CO}_{3}$ and $100 \mathrm{~nm}$ thick Al layers were evaporated as the cathode. The EL spectra were measured using a PR655 spectra colorimeter. The current density-voltage and brightness-voltage curves of the devices were plotted using a Keithley 2400 source meter calibrated by a silicon photodiode. All the measurements were carried out at room temperature with no protective encapsulation. The EQE was calculated from the brightness, current density and EL spectrum assuming a Lambertian distribution.

\section{Synthesis of Materials}

\section{Synthesis of 2-methoxy-9,9'-spirobi[fluorene] (MO-SP)}

The 2-bromo-9,9 'spirobi[fluorene] (5.0 g, $12.70 \mathrm{mmol}$ ) was dissolved in $50 \mathrm{ml} \mathrm{DMF}$ and then added into the sodium methoxide solution ( $30 \mathrm{ml}, 14.5 \mathrm{mmol}$ ) and cuprous iodide ( 2.8 $\mathrm{g}, 14.9 \mathrm{mmol})$. The reaction was heated at $120^{\circ} \mathrm{C}$ at the atmosphere of nitrogen for $12 \mathrm{~h}$. After cooling, $100 \mathrm{~mL}$ water was poured into the mixer, and then the dichloromethane was used to extract the organic solution of crude products for three times. The crude product was purified by the silica gel column

Table 2 Summary of solution-processed OLED

\begin{tabular}{|c|c|c|c|c|c|c|c|}
\hline EML & $\mathrm{V}_{\text {on }}{ }^{\mathrm{a}}[\mathrm{V}]$ & $L_{\max }^{b}\left[\mathrm{~cd} \mathrm{~m}^{-2}\right]$ & $\Phi_{\mathrm{F}}{ }^{\mathrm{c}}[\%]$ & $C E_{\max }{ }^{d}\left[c d A^{-1}\right]$ & $\mathrm{PE}_{\max }{ }^{\mathrm{e}}\left[\operatorname{lm~W} \mathrm{W}^{-1}\right]$ & $\operatorname{EQE}_{\max }{ }^{\mathrm{f}}[\%]$ & $\operatorname{CIE}(x, y)^{g}$ \\
\hline $5 \mathrm{CzBN}-\mathrm{SSP}$ & 3.4 & 5400 & 38.0 & 21.9 & 17.2 & 7.3 & {$[0.28,0.54]$} \\
\hline 5CzBN-DSP & 3.2 & 14800 & 45.7 & 40.7 & 31.9 & 13.9 & {$[0.27,0.54]$} \\
\hline 5CzBN-PSP & 3.1 & 13700 & 69.6 & 58.7 & 46.2 & 20.1 & {$[0.27,0.53]$} \\
\hline
\end{tabular}

${ }^{a} V_{o n}=$ turn-on voltage at $1 c d m^{-2},{ }^{f} L_{\max }=$ maximum luminance, $\Phi_{F}{ }^{c}=$ the photoluminescence quantum yield of neat films. ${ }^{d} C E_{\max }=$ maximum current efficiency, ePE $E_{\max }$ $=$ maximum power efficiency, ${ }^{\mathrm{f}} \mathrm{EQE} \mathrm{E}_{\max }=$ maximum external quantum efficiency, ${ }^{\mathrm{g}} \mathrm{ClE}=$ the Commission Internationale de $\mathrm{L}^{\prime} \mathrm{Eclairage}$ coordinates at $10 \mathrm{~V}$ 
chromatography and the selected eluent was petroleum ether and dichloromethane. Finally, the white product was obtained (3.83 g, 87.2\%). ${ }^{1} \mathrm{H}-\mathrm{NMR}\left(600 \mathrm{MHz}, \mathrm{CDCl}_{3}\right.$ ) $\delta[\mathrm{ppm}]:$ 7.8-7.86(d, $2 \mathrm{H}), 7.71-7.76(\mathrm{~d}, 2 \mathrm{H}), 7.29-7.39(\mathrm{~m}, 3 \mathrm{H}), 7.01-7.14(\mathrm{~m}, 3 \mathrm{H}), 6.99-$ 7.05(m, 1H), 6.88-6.94(m, 1H), 6.76-6.71(d, $1 \mathrm{H}), 6.63-6.68(\mathrm{~d}$, $1 \mathrm{H}), 6.21-6.27(\mathrm{~d}, 1 \mathrm{H}), 3.54-3.69(\mathrm{~s}, 3 \mathrm{H}) .{ }^{13} \mathrm{C}-\mathrm{NMR}\left(75 \mathrm{MHz}, \mathrm{CDCl}_{3}\right.$, ठ): 160.0, 142.9, 141.9, 141.0, 133.3, 129.4, 128.7, 128.1, 126.7, $126.2,112.8,112.3,63.2,55.8$. $\mathrm{MS}[\mathrm{m} / \mathrm{z}]$ : calculated for $\mathrm{C}_{26} \mathrm{H}_{18} \mathrm{O}$, 346.14; found, [346.42] +. Elemental analysis (\%): Calcd for $\mathrm{C}_{26} \mathrm{H}_{18} \mathrm{O}: \mathrm{C}, 90.14 ; \mathrm{H}, 5.24$. Found: $\mathrm{C}, 90.23 ; \mathrm{H}, 5.31$.

\section{Synthesis of 9,9'-spirobi[fluoren]-2-ol (OH-SP)}

Take 3-methoxyl-9,9 'conodium [fluorene](2.5 g, $7.2 \mathrm{mmol}$ ) and dissolved in $10 \mathrm{~mL}$ anhydrous dichloromethane. Take boron tribromide (4 g, $15.87 \mathrm{mmol}$ ) was slowly added in $\mathrm{CH}_{2} \mathrm{Cl}_{2}(10 \mathrm{~mL})$, then mixed them slowly at $0^{\circ} \mathrm{C}$. The reaction was finished after stirring for 4 hours at room temperature. The solution was purified by column chromatography by silica gel column chromatography. The solvent was petroleum ether and dichloromethane. the white solid OH-SP have got (1.93 g, 81.0\%). ${ }^{1} \mathrm{H}-\mathrm{NMR}\left(600 \mathrm{MHz}, \mathrm{CDCl}_{3}\right)$ 8: 7.78-7.80(d, $\left.2 \mathrm{H}\right), 7.66$ 7.76(d, $2 \mathrm{H}), 7.29-7.39(\mathrm{~m}, 4 \mathrm{H}), 7.07-7.13(\mathrm{~m}, 2 \mathrm{H}), 7.00-7.06(\mathrm{~m}$, $1 \mathrm{H}), 6.66-6.84(\mathrm{~d}, 4 \mathrm{H}), 6.11-6.18(\mathrm{~m}, 1 \mathrm{H}) .{ }^{13} \mathrm{C}-\mathrm{NMR}(75 \mathrm{MHz}$, $\left.\mathrm{CDCl}_{3}, \delta\right): 156.4,143.3,141.9,141.0,133.6,129.8,129.2,128.7$, 128.1, 126.7, 126.2, 114.4, 113.9, 63.2. MS [m/z]: calculated for $\mathrm{C}_{25} \mathrm{H}_{16} \mathrm{O}, 332.12$; found, 332.10. Elemental analysis (\%): Calcd. For $\mathrm{C}_{25} \mathrm{H}_{16} \mathrm{O}: \mathrm{C}, 90.33 ; \mathrm{H}, 4.85$. Found: $\mathrm{C}, 90.27, \mathrm{H}, 4.92$.

\section{Synthesis of 4-((6-bromohexyl) oxy)-9H-carbazole (Br-Cz)}

Take 9-hydrogen-carbazole-4-hydroxyl (3.0 g, $16.4 \mathrm{mmol}), 1,6-$ dibromohexane $(16.0 \mathrm{~g}, 65.6 \mathrm{mmol})$ and cesium carbonate $(20$

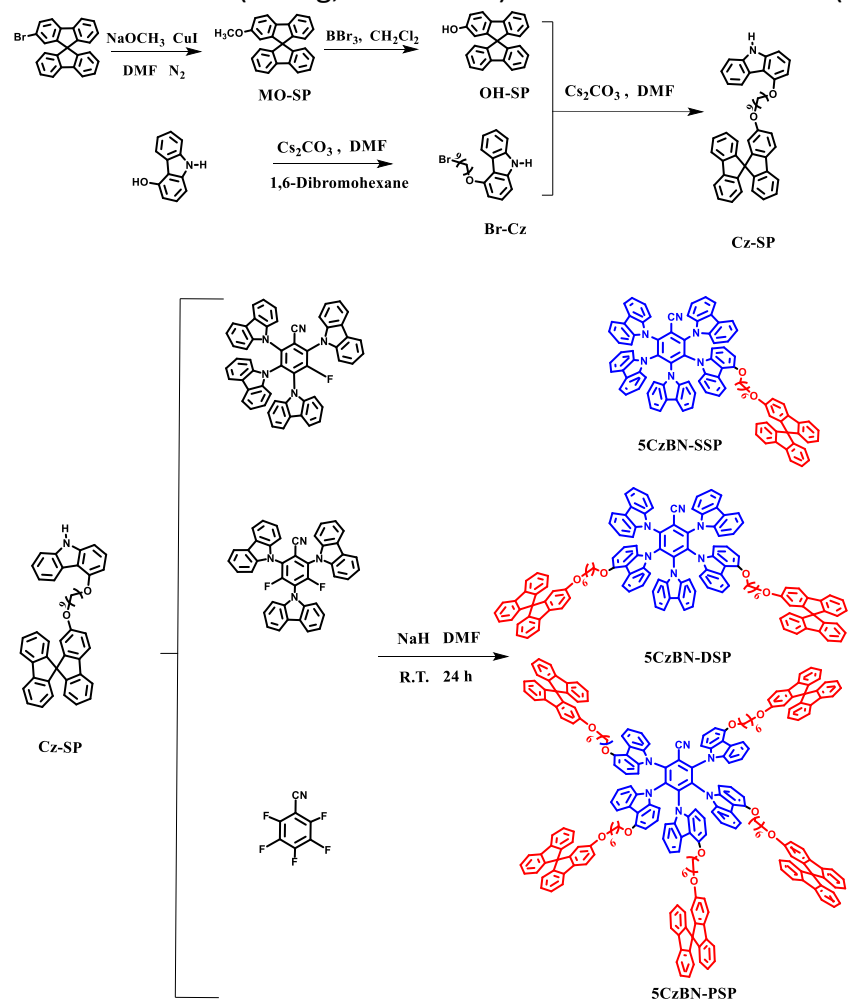

Scheme 1 Synthetic routes and chemical structures of $5 \mathrm{C} z \mathrm{BN}-\mathrm{SSP}, 5 \mathrm{CzBN}-\mathrm{DSP}$ and 5 CzBN-PSP. $\mathrm{g}, 61.3 \mathrm{mmol}$ ) in a $50 \mathrm{ml}$ bottle, then pour $20 \mathrm{ml} \mathrm{DMF}$ in it, stirring under nitrogen for $90 \mathrm{~min}$. After that, the mixture was poured into $100 \mathrm{~mL}$ water to precipitate the product. After separation and purification by chromatography column with the petroleum ether and dichloromethane, and the white solid was obtained. (3.1 g, yield 55.0\%). ${ }^{1} \mathrm{H}-\mathrm{NMR}\left(600 \mathrm{MHz}, \mathrm{CDCl}_{3}\right) \delta$ : 8.26-8.34(d, $1 \mathrm{H}), 7.94-8.04(\mathrm{~s}, 1 \mathrm{H}), 7.20-7.44(\mathrm{~m}, 4 \mathrm{H}), 6.97-$ 7.04(d, $1 \mathrm{H}), 6.60-6.67(\mathrm{~d}, 1 \mathrm{H}), 4.17-4.27(\mathrm{~m}, 2 \mathrm{H}), 3.36-3.48(\mathrm{~m}$, $2 \mathrm{H}), 1.52-2.08(\mathrm{~m}, 8 \mathrm{H}) .{ }^{13} \mathrm{C}-\mathrm{NMR}\left(75 \mathrm{MHz}, \mathrm{CDCl}_{3}, \delta\right): 149.0,141.3$, $130.2,128.3,124.1,121.7,121.4,121.3,119.8,111.1,107.6$, 102.7, 69.0, 33.7, 32.6, 29.6, 25.4, 24.9. MS (MALDI-TOF) [m/z]: calculated for $\mathrm{C}_{18} \mathrm{H}_{20} \mathrm{BrNO}, 345.07$; found, 345.11. Elemental analysis. Calcd. For $\mathrm{C}_{18} \mathrm{H}_{20} \mathrm{BrNO}: \mathrm{C}, 62.44 ; \mathrm{H}, 5.82 ; \mathrm{Br}, 23.08 ; \mathrm{N}$, 4.05. Found: $\mathrm{C}, 62.28 ; \mathrm{H}, 5.64 ; \mathrm{Br}, 23.21, \mathrm{~N}, 4.01$.

Synthesis of 4 - ((6- (9,9'-fluorene) -2-hydroxyl) hexyl) hydroxyl) -9h-carbazole (Cz-SP)

A mixer of OH-SP $(1.8 \mathrm{~g}, 5.4 \mathrm{mmol})$ and $\mathrm{Br}-\mathrm{Cz}(2.1 \mathrm{~g}, 6.1 \mathrm{mmol})$ into a $50 \mathrm{ml}$ bottle, then added cesium carbonate $\left(\mathrm{C}_{\mathrm{S}_{2}} \mathrm{CO}_{3}, 10 \mathrm{~g}\right.$, $30.7 \mathrm{mmol}$ ) in it, $15 \mathrm{ml}$ DMF was added in to the mixture and stirred for $1.5 \mathrm{~h}$ at room temperature under nitrogen, and then poured $100 \mathrm{~mL}$ water in the mixture was extracted with $\mathrm{CH}_{2} \mathrm{Cl}_{2}$ three times. Then the combined organic layer was dried over anhydrous $\mathrm{NaSO}_{4}$, and under vacuum the solvent was removed. Finally, the crude product was purified by column chromatography on silica gel, white product was obtained (3.06 g, 95\%). ${ }^{1} \mathrm{H}-\mathrm{NMR}\left(600 \mathrm{MHz}, \mathrm{CDCl}_{3}\right) \delta: 11.21(\mathrm{~s}, 1 \mathrm{H}), 8.24-8.28(\mathrm{~d}$, $1 \mathrm{H}), 7.95-8.02(\mathrm{~s}, 1 \mathrm{H}), 7.80-7.84(\mathrm{~m}, 2 \mathrm{H}), 7.04-7.76(\mathrm{~m}, 2 \mathrm{H}), 7.27-$ $7.38(\mathrm{~m}, 6 \mathrm{H}), 7.17-7.20(\mathrm{~m}, 1 \mathrm{H}), 7.07-7.14(\mathrm{~m}, 2 \mathrm{H}), 6.98-7.05(\mathrm{~m}$, $2 \mathrm{H}), 6.87-6.90(\mathrm{~d}, 1 \mathrm{H}), 6.73-6.77(\mathrm{~d}, 1 \mathrm{H}), 6.59-6.67(\mathrm{~d}, 2 \mathrm{H}), 6,23-$ 6.28(d, $1 \mathrm{H}), 4.14-4.21(\mathrm{~m}, 2 \mathrm{H}), 3.75-3.80(\mathrm{~m}, 2 \mathrm{H}), 1.92-1.98(\mathrm{~m}$, $2 \mathrm{H}), 1.45-1.74(\mathrm{~m}, 6 \mathrm{H}) .{ }^{13} \mathrm{C}-\mathrm{NMR}\left(75 \mathrm{MHz}, \mathrm{CDCl}_{3}, \delta\right): 156.8,149.0$ $142.5,141.9,141.3,141.0,132.6,130.2,129.0,128.7,128.1$, 126.7, 126.2, 119.8, 112.9, 112.4, 111.1, 107.6, 102.7, 69.0, 68.7, 29.6, 25.9. MS (MALDI-TOF) [m/z]: calculation for $\mathrm{C}_{43} \mathrm{H}_{35} \mathrm{NO}_{2}$, 597.26; found, 597.47. Elemental analysis. Calcd. For $\mathrm{C}_{43} \mathrm{H}_{35} \mathrm{NO}_{2}$ : C, 86.4; H, 5.90; N, 2.34. Found: C, 86.43; H, 5.89, N, 2.32.

Synthesis of 2,3,4,5, 6-5 (4 - ((9,9' -fluorene) -2-hydroxyl) ethyl) -9h-carbazole-9-yl) benzonitrile (5CzBN-PSP)

Take Cz-SP $(1.0 \mathrm{~g}, 1.67 \mathrm{mmol})$ in anhydrous THF $(10 \mathrm{~mL})$, then added sodium hydride $(0.14 \mathrm{~g}, 6.01 \mathrm{mmol})$ in the mixture, stirred in nitrogen atmosphere for $0.5 \mathrm{~h}$. then 2,3,4,5, 6pentafluoronitrile $(0.054 \mathrm{~g}, 0.28 \mathrm{mmol})$ was slowly added in it. Under nitrogen atmosphere the mixture was stirred at room temperature for $72 \mathrm{~h}$. After that, water was added slowly to quench the excess $\mathrm{NaH}$, and then, $200 \mathrm{~mL}$ of water was added into the mixture solution and extracted with the $\mathrm{CH}_{2} \mathrm{Cl}_{2}$ three times. The organic liquid was dried with anhydrous sodium sulfate and the solvent was removed under vacuum. The final product was separated by silica gel column chromatography. Finally, the bright green solid powder was obtained $(0.51 \mathrm{~g}$, yield $50 \%)$. ${ }^{1} \mathrm{H}-\mathrm{NMR}\left(600 \mathrm{MHz}, \mathrm{CDCl}_{3}\right)$ 8: 7.86-7.91(s, $\left.2 \mathrm{H}\right), 7.57-$ $7.81(\mathrm{~m}, 20 \mathrm{H}), 7.41-7.51(\mathrm{~m}, 3 \mathrm{H}), 7.26-7.34(\mathrm{~m}, 15 \mathrm{H}), 6.98-7.18(\mathrm{~m}$, $23 \mathrm{H}), 6.89-6.94(\mathrm{~m}, 4 \mathrm{H}), 6.65-6.85(\mathrm{~m}, 27 \mathrm{H}), 6.37-6.61(\mathrm{~m}, 8 \mathrm{H})$, $6.13-6.23(\mathrm{~m}, 5 \mathrm{H}), 6.03-6.08(\mathrm{~d}, 3 \mathrm{H}), 3.54-4.00(\mathrm{~m}, 20 \mathrm{H})$, 1.381.81(m, 40H). ${ }^{13} \mathrm{C}-\mathrm{NMR}\left(75 \mathrm{MHz}, \mathrm{CDCl}_{3}, \delta\right): 159.4,156.2,150.5$, $150.0,148.2,145.4,141.6,134.4,127.8,127.7,126.5,124.1$, $120.6,119.9,119.1,116.6,114.1,110.0,102.5,67.8,66.0,34.7$, 
29.1, 29.0, 26.8, 26.0, 25.7. MS (MALDI-TOF) [m/z]: calculation for $\mathrm{C}_{222} \mathrm{H}_{170} \mathrm{~N}_{6} \mathrm{O}_{10}, 3081.30$, found, 3081.84, Elemental analysis. Calcd. For $\mathrm{C}_{222} \mathrm{H}_{170} \mathrm{~N}_{6} \mathrm{O}_{10}$ : C, 86.52; $\mathrm{H}, 5.56 ; \mathrm{N}, 2.73$. Found: $\mathrm{C}$, 86.53; H, 5.55, N, 2.72.

Synthesis of 3,5-bis(4-((6-(9,9'-spirobi[fluoren]-2-yloxy)hexyl) oxy)-9H-carbazol-9-yl)-2,4,6-tri(9H-carbazol-9-yl)benzonitrile. (5CzBN-DSP)

The synthesis procedure of this compound is referred to $5 \mathrm{CzBN}$ PSP. (0.51 g, 57\%) ${ }^{1} \mathrm{H}-\mathrm{NMR}\left(600 \mathrm{MHz}, \mathrm{CDCl}_{3}\right) \delta:$ 7.69-8.02(m, $19 \mathrm{H}), 7.25-7.44(\mathrm{~m}, 12 \mathrm{H}), 7.02-7.15(\mathrm{~m}, 14 \mathrm{H}), 6.88-6.93(\mathrm{~m}, 2 \mathrm{H})$, $6.53-6.60(\mathrm{~m}, 15 \mathrm{H}), 6.19-6.25(\mathrm{~d}, 3 \mathrm{H}), 6.01-6.08(\mathrm{~s}, 2 \mathrm{H}), 5.72-$ 5.77(s, 1H), 3.64-3.82(m, 8H), 1.35-1.63(m, 16H). ${ }^{13} \mathrm{C}-\mathrm{NMR}(75$ $\left.\mathrm{MHz}_{2} \mathrm{CDCl}_{3}, \delta\right): 159.3,154.6,150.6,149.0,148.4,141.5,140.4$, $139.3,137.9,136.7,134.5,127.8,126.6,125.3,124.1,123.8$, 120.7, 120.0, 119.0, 116.8, 114.0, 110.0, 109.7, 103.4, 67.8, 67.4, 66.0, 28.8, 26.9, 25.4. MS (MALDI-TOF) [m/z]: calculation for $\mathrm{C}_{129} \mathrm{H}_{92} \mathrm{~N}_{6} \mathrm{O}_{4}, 1788.72$; found, 1788.73. Elemental analysis. Calcd. For $\mathrm{C}_{129} \mathrm{H}_{92} \mathrm{~N}_{6} \mathrm{O}_{4}: \mathrm{C}, 86.55 ; \mathrm{H}, 5.18 ; \mathrm{N}, 4.69$. Found: $\mathrm{C}, 86.58 ; \mathrm{H}$, $5.15, \mathrm{~N}, 4.68$.

Synthesis of 3-(4-((6-(9,9'-spirobi[fluoren]-2-yloxy)hexyl)oxy) 9H-carbazol-9-yl)-2,4,5,6-tetra(9H-carbazol-9-yl)benzonitrile (5CzBN-SSP)

The synthesis procedure of this compound is referred to $5 \mathrm{CzBN}$ PSP. (0.47 g, 52\%) $1 \mathrm{H}-\mathrm{NMR}(600 \mathrm{MHz}, \mathrm{CDCl} 3) \delta: 7.64-8.02(\mathrm{~m}$, $17 \mathrm{H}), 7.27-7.45(\mathrm{~m}, 9 \mathrm{H}), 6.98-7.18(\mathrm{~m}, 11 \mathrm{H}), 6.88-6.94(\mathrm{~m}, 1 \mathrm{H})$, 6.47-6.76(m, 14H), 6.21-6.26(m, $1 \mathrm{H}), 5.99-6.06(\mathrm{~m}, 1 \mathrm{H}), 3.67-$ $3.85(\mathrm{~m}, 4 \mathrm{H}), 1.35-1.64(\mathrm{~m}, 8 \mathrm{H}) .13 \mathrm{C}-\mathrm{NMR}(75 \mathrm{MHz}, \mathrm{CDCl} 3$, ठ):159.3, 154.6, 150.5, 149.0, 148.4, 141.8, 140.5, 139.2, 139.0, $137.7,137.0,136.4,128.0,127.8,126.5,125.3,124.1,124.0$, $123.9,122.2,121.1,120.9,120.5,120.0,119.4,116.9,114.0$, 113.0, 112.7, 110.3, 109.6, 103.4, 102.8, 67.8, 67.4, 65.8, 29.1, 28.9, 26.9, 25.7. MS (MALDI-TOF) [m/z]: calculation for $\mathrm{C}_{98} \mathrm{H}_{66} \mathrm{~N}_{6} \mathrm{O}_{2}, 1358.52$; found, 1358.33. Elemental analysis. Calcd. For $\mathrm{C}_{98} \mathrm{H}_{66} \mathrm{~N}_{6} \mathrm{O}_{2}: \mathrm{C}: 86.57, \mathrm{H}: 4.89, \mathrm{~N}: 6.18$. Found: $\mathrm{C}, 86.55 ; \mathrm{H}$, 4.91, N, 4.06 .

\section{Conflicts of interest}

There are no conflicts to declare.

\section{Acknowledgements}

We are grateful for the grants from the National Natural Science Foundation of China (21875036 and 51103023), the Fundamental Research Funds for the Central Universities. We are also thankful for the support of the Scientific Research Foundation of Graduate School of Southeast University (YBPY1975), the Priority Academic Program Development of Jiangsu Higher Education Institutions, Nanjing science and technology committee.

\section{References}

1 J. J. Luo, G. H. Xie, S. L. Gong, T. H. Chen, C. L. Yang, Chem. Commun., 2016, 52, 2292-2295.

2 N. Aizawa, Y.-J. Pu, T. Chiba, S. Kawata, H. Sasabe, J. Kido, Adv. Mater., 2014, 26, 7543-7546.
3 F. K. Kong, M. C. Tang, Y. C. Wong, M. Y. Chan, V. W. Yam, J. Am. Chem. Soc., 2016, 138, 6281-6291.

4 H. Liu, Q. Bai, L. Yao, D. Hu, X. Tang, F. Shen, H. Zhang, Y. Gao, P. Lu, B. Yang, Y. Ma, Adv. Funct. Mater., 2014, 24, 5881-5888.

5 Y. Zou, J. H. Zou, T. L. Ye, H. Li, C. L. Yang, H. B. Wu, D. G. Ma, J, G. Qin, Y. Cao, Adv. Funct. Mater., 2013, 23, 1781-1788.

6 K. Albrecht, K. Matsuoka, K. Fujita and K. Yamamoto, Angew. Chem. Int. Ed., 2015, 54, 5677-5682.

7 H. Uoyama, K. Goushi, K. Shizu, H. Nomura, C. Adachi, Nature, 2012, 492, 234-238.

8 Y. Tao, K. Yuan, T. Chen, P. Xu, H. H. Li, R. Chen, C. Zheng, L. Zhang, W. Huang, Adv. Mater., 2014, 26, 7931-7958.

9 Z. Y. Yang, Z. Mao, Z. L. Xie, Y. Zhang, S. W. Liu, J. Zhao, J. R. Xu, Z. G. Chi, M. P. Aldred, Chem. Soc. Rev., 2017, 46, 915-1016.

10 Y. Suzuki, Q. Zhang, C. Adachi, J. Mater. Chem. C, 2015, 3, 1700-1706.

11 Y. J. Cho, B. D. Chin, S. K. Jeon, J. Y. Lee, Adv. Funct. Mater., 2015, 25, 6786-6792.

12 L. Yu, Z. B. Wu, G. H. Xie, C. Zhong, Z. Zhu, H. J. Cong, D. G. Ma, C. L. Yang, Chem. Commun., 2016, 52, 11012-11015.

13 G. Z. Xie, X. L. Li, D. J. Chen, Z. H. Wang, X. Y. Cai, D. C. Chen, Y. C. Li, K. K. Liu, Y. Cao, S. J. Su, Adv. Mater., 2016, 28, 181-187.

14 Y. F. Li, G. H. Xie, S. L. Gong, K. L. Wu, C. L. Yang, Chem. Sci., 2016, 7, 5441-5447.

15 Q. Zhang, D. Tsang, H. Kuwabara, Y. Hatae, B. Li, T. Takahashi, S. Y. Lee, T. Yasuda, C. Adachi, Adv. Mater., 2015, 27, 2096 2100.

16 B. Guo, X. Cai, S. Xu, S. M. A. Fateminia, J. Liu, J. Liang, G. Feng, W. Wu and B. Liu, J. Mater. Chem. B, 2016, 4, 4690-4695.

17 W. Z. Yuan, P. Lu, S. M. Chen, J. W. Y. Lam, Z. M. Wang, Y. Liu, H. S. Kwok, Y. G. Ma, B. Z. Tang, Adv. Mater., 2010, 22, 21592163.

18 X. Y. Cai, X. L. Li, G. Z. Xie, Z. Z. He, K. Gao, K. K. Liu, D. C. Chen, Y. Cao, S. J. Su. Chem. Sci., 2016, 7, 4264-4275.

$19 \mathrm{M}$. Inoue, T. Serevicius, H. Nakanotani, K. Yoshida, T. Matsushima, S. Juresenas, C. Adachi. Chem. Phys. Lett., 2016, 644, 62-67.

20 J. D. Luo, Z. L. Xie, J. W. Y. Lam, L. Cheng, H. Y. Chen, C. F. Qiu, H. S. Kwok, X. W. Zhan, Y. Q. Liu, D. B. Zhu and B. Z. Tang, Chem Commun., 2001, 1740-1741.

21 J. Mei, Y. N. Hong, J.W. Lam, A. J. Qin, Y. H. Tang, B. Z. Tang. Adv. Mater., 2014, 26, 5429-5479.

22 R. T. K. Kwok, C. W. T. Leung, J. W. Y. Lam, B. Z. Tang. Chem. Soc. Rev., 2015, 44, 4228-4238.

23 T. Shan, Y. L. Liu, X. Y. Tang, Q. Bai, Y. Gao, Z. Gao, J. Y. Li, J. Deng, B. Yang, P. Lu and Y. G. Ma, ACS Appl. Mater. Interfaces, 2016, 8, 28771-28779.

24 H. J. Liu, J. J. Zeng, J. J. Guo, H. Nie, Z. J. Zhao, B. Z. Tang. Angew. Chem. Int. Ed., 2018, 57, 9290-9294.

25 J. Guo, J. Fan, L. Lin, J. Zeng, H. Liu, C.-K. Wang, Z. Zhao, B. Z. Tang, Adv. Sci., 2019, 6, 1801629.

26 H. Liu, J. J. Guo, Z. J. Zhao, B. Z. Tang, ChemPhotoChem, 2019, 3, 993-999.

27 S. D. Xu, T. T. Liu, Y. X. Mu, Y. F. Wang, Z. G. Chi, C. C. Lo, S. W. Liu, Y. Zhang, A. Lien, J. R. Xu, Angew. Chem. Int. Ed., 2015, 54, 874-878.

28 Z. L. Xie, C. J. Chen, S. D. Xu, J. Li, Y. Zhang, S. W. Liu, J. R. Xu, Z. G. Chi, Angew. Chem. Int. Ed., 2015, 54, 7181-7184.

29 W. W. H. Lee, Z. Zhao, Y. J, Cai, Z. Xu, Y. Yu, Y. Xiong, R. T. K. Kwok, Y. Chen, N. L. C. Leung, D. G. Ma, J. W. Y. Lam, A. J. Qin, B. Z. Tang. Chem. Sci., 2018, 9, 6118-6125.

30 H. J. Kim, S. K. Kim, M. Godumala, J. Yoon, C. Y. Kim, J. E. Jeong, H. Y. Woo, J. H. Kwon, M. J. Cho, D. H. Choi, Chem. Commun., 2019, 55, 9475-9478.

31 D. Liu, W. W. Tian, Y. L.Feng, X. S. Zhang, X. X. Ban, W. Jiang, Y. M. Sun, ACS Appl. Mater. Interfaces, 2019, 11, 16737-16748. 
32 S. Gan, S. Hu, X. L. Li, J. Zeng, D. Zhang, T. Huang, W. Luo, Z. Zhao, L. Duan, S. J. Su and B. Z. Tang, ACS Appl. Mater. Interfaces, 2018, 10, 17327-17334.

33 S. Chen, P. Zeng, W. Wang, X. Wang, Y. Wu, P. Lin and Z. Peng, J. Mater. Chem. C, 2019, 7, 2886-2897.

34 C. Wang, X. Li, Y. Pan, S. Zhang, L. Yao, Q. Bai, W. Li, P. Lu, B. Yang, S. Su and Y. Ma, ACS Appl. Mater. Interfaces, 2016, 8, 3041-3049.

35 K. Bhattacharyya, M. Chowdhury, Chem. Rev. 1993, 93, 507535.

36 M. A. Haidekker, E. A. Theodorakis, Org. Biomol. Chem., 2007 5, 1669-1678.

37 V. B. Koutecky, J. Koutecky, J. Michl, Angew. Chem, Int. Ed. Engl. 1987, 26, 170-189.

38 R. R. Hu, E. Lager, A. Aguilar, J. Z. Liu, J. W. Y. Lam, H. H. Y. Sung, I. D. Williams, Y. C. Zhong, K. S. Wong, E. P. Cabrera, B. Z. Tang, J. Phys. Chem. C 2009, 113, 15845-15853.

39 J. Guo, X. L. Li, H. Nie, W. Luo, R. Hu, A. Qin, Z. Zhao, S. J. Su, B. Z. Tang, Chem. Mater., 2017, 29, 3623-3631.

40 S. M. Wang, B. H. Zhang, Y. Wang, J. Q. Ding, Z. Y. Xie, L. X. Wang, Chem. Commun., 2017, 53, 5128-5131.

41 Y. Yang, S. Wang, Y. Zhu, Y. Wang, H. Zhan and Y. Cheng, Adv. Funct. Mater., 2018, 28, 1706916.

Constructing core-dendron TADF emitters systematically: changing the behaviour of chromophores from aggregation-caused quenching to aggregation induced emission to develop high-performance fully solution-processed nondoped OLEDs.

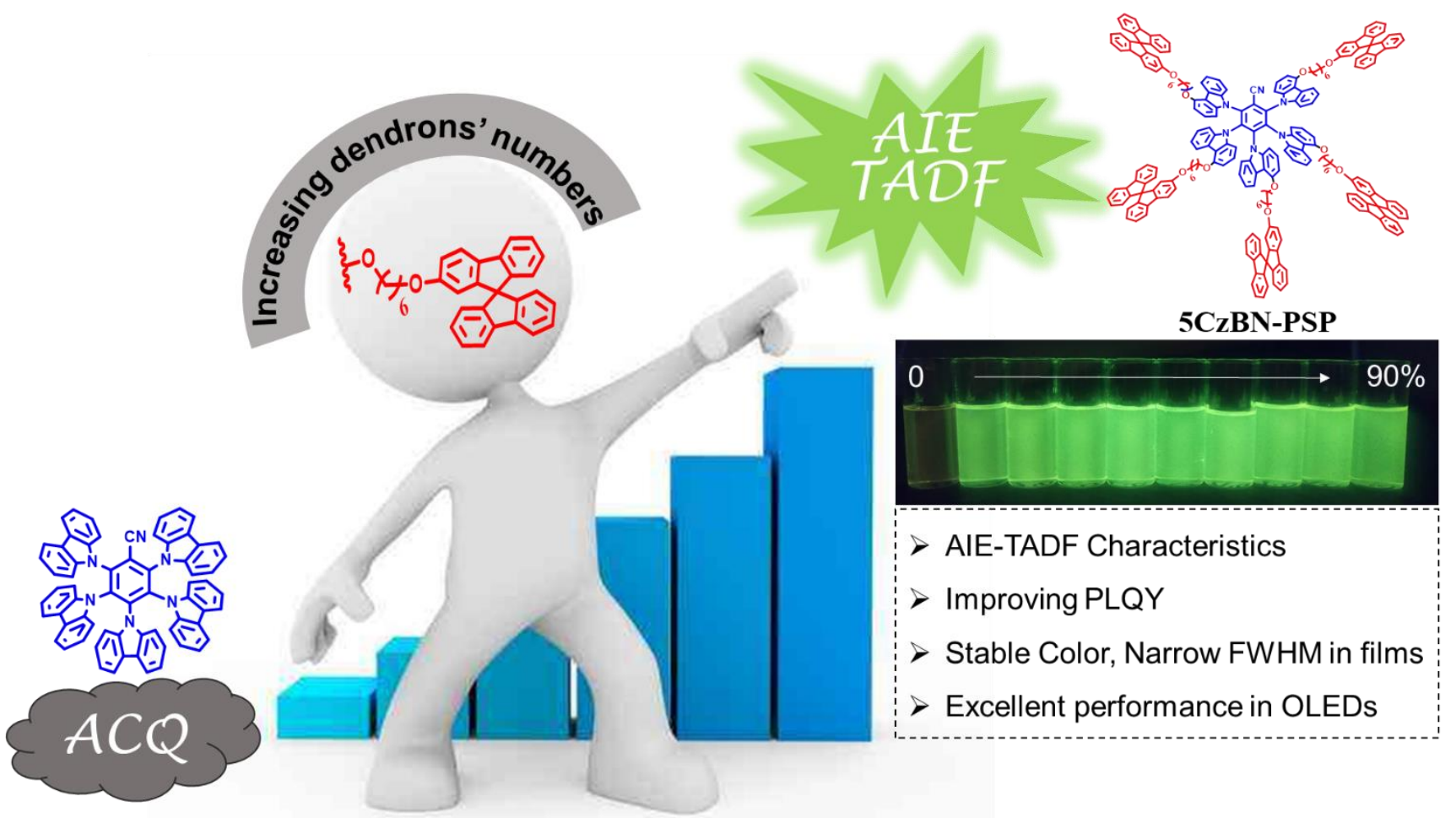

